\title{
Bi-atrial myxomas presenting as recurrent pulmonary emboli in a girl
}

\author{
JOHN HANLY \\ M.B., M.R.C.P.I. \\ KEITH SHAW \\ M.D., F.R.C.S.I.
}

MICHAEL DE BUITLEIR

M.B., M.R.C.P.I.

BRIAN MAURER

M.B., F.R.C.P.I.

\author{
M. X. FitzGERALD \\ MD., F.R.C.P., F.R.C.P.I.
}

Departments of Respiratory Medicine, Cardiology, and Thoracic Surgery, St Vincent's Hospital, Elm Park, Dublin 4.

\begin{abstract}
Summary
A 14-year-old girl whose sole presenting features were symptoms of pulmonary embolism, was found to have bi-atrial myxomas. The diagnosis was made preoperatively, and the patient had a successful outcome following elective surgery. The absence of other features such as systemic embolism, atrioventricular valvular obstruction, fever and constitutional symptoms makes this a most unusual case. Right atrial myxoma should be considered in any patient presenting with pulmonary embolism for which there is no obvious source.
\end{abstract}

KEY WORDS: myxoma, pulmonary embolism, lentigines.

\section{Introduction}

Myxomas account for $50 \%$ of primary cardiac tumours, and characteristically present with one or more of the following: symptoms of atrio-ventricular valvular obstruction, systemic embolism, non-specific constitutional symptoms, such as fever and weight loss, together with anaemia, an elevated erythrocyte sedimentation rate (ESR) and raised serum gammaglobulin (Sutton et al., 1980). About $75 \%$ of myxomas are found in the left atrium, $20 \%$ in the right atrium and 5\% in the ventricles (Goodwin, 1963). Although there have been twenty-two reported cases of biatrial myxomas (Sutton et al., 1980; Imperio et al., 1980; Fitterer, Spicer and Nelson, 1976; Herpin et al., 1980; Carvalho et al., 1980), the majority of these were not diagnosed until autopsy, or unexpectedly at exploratory surgery.

We report an unusual case of bi-atrial myxomas in a patient who presented solely with recurrent pulmonary emboli, and had successful surgery following pre-operative diagnosis.

\section{Case report}

A 14-year-old girl was admitted to St Vincent's Hospital in July 1981, with a history of recurrent bilateral pleuritic chest pain on three separate occasions over the preceding 6 months. She also complained of loss of energy for the same period of time. Her past history was unremarkable.

General examination was normal, but multiple unusual dark brown freckles were noted around the nose and malar areas. Cardiovascular findings were variable but at different times the following were noted: a third heart sound, a grade $2 / 6$ 'to and fro' systolic murmur, best heard at the left sternal border, and an evanescent friction rub.

The erythrocyte sedimentation rate (Westergren) was elevated to $21 \mathrm{~mm}$ in the first hour, but fell to normal pre-operatively. Haemoglobin concentration was normal. Liver function tests showed a slight elevation of all hepatic enzymes. An electrocardiogram was normal and a chest X-ray revealed a small right-sided pleural effusion. A ventilation-perfusion scan showed perfusion defects in both lung fields, and normal ventilation (Fig. 1)-a pattern suggestive of multiple pulmonary emboli. Serological markers for collagen-vascular disease were absent, but immune electrophoresis revealed an elevated $\mathrm{IgG}$ level of $22 \cdot 1 \mathrm{~g} /$ litre (normal range $8-18 \mathrm{~g} /$ litre), with normal IgM and IgA levels. Doppler and isotope venograms showed normal venous drainage from both lower limbs, and ultrasound examination of the pelvis was normal. One-dimensional echocardiography revealed a sonic mass in the left atrium, and a similar lesion in the right atrium (Fig. 2). Angiocardiography showed a left atrial filling defect, and in addition, a mass lesion in the right atrium. These 


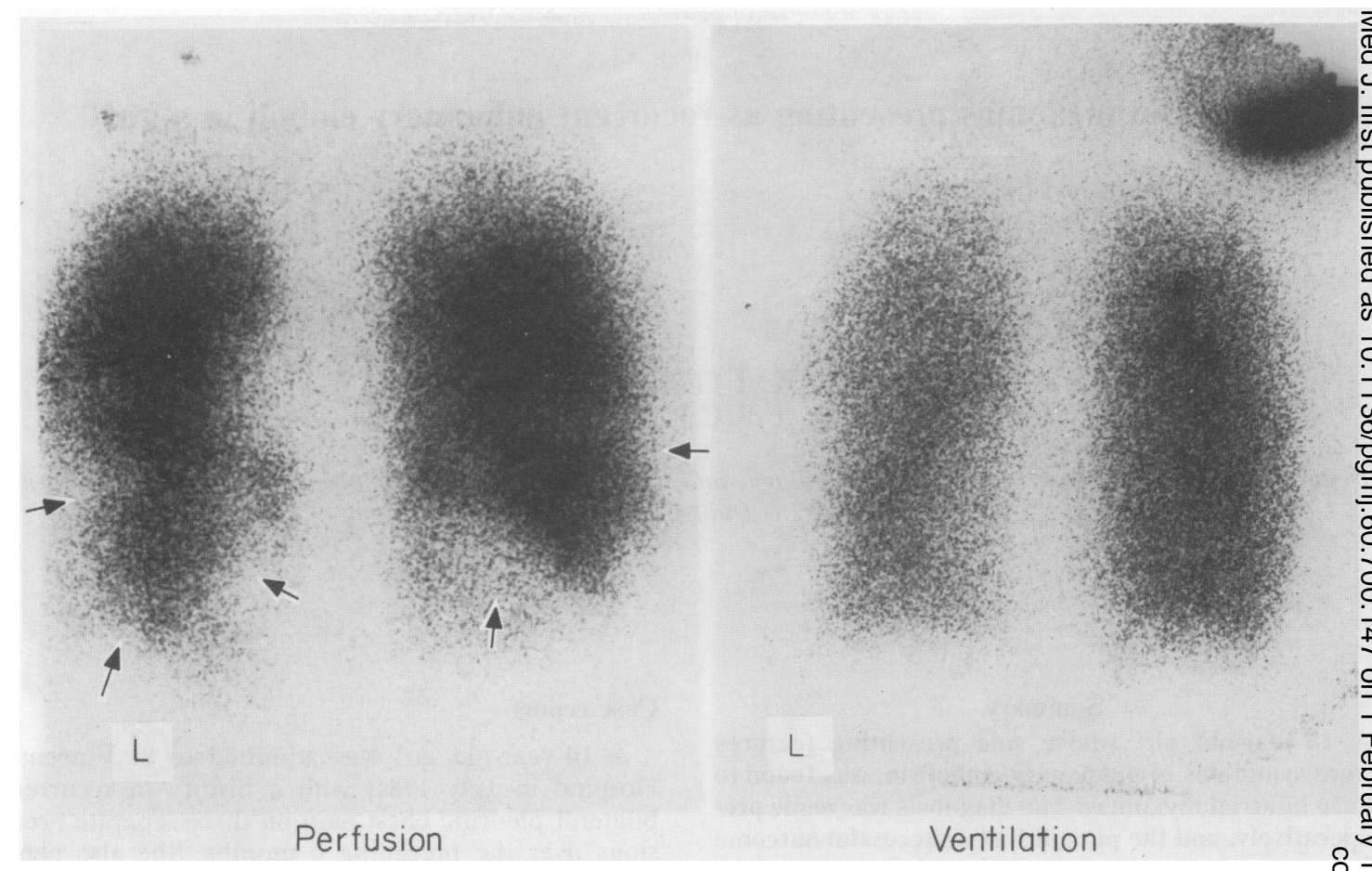

FiG. 1. Ventilation (Krypton $81-\mathrm{m}$ ) perfusion lung scan, showing multiple perfusion defects (arrows) to both lungs and normal ventilation $\vec{\theta}$ suggestive of multiple pulmonary emboli.

findings were confirmed by two-dimensional echocardiography.

At surgery, a right cardiotomy revealed a large soft myxoma, filling the right atrium and extending into the inferior vena cava and tricuspid valves. The interatrial septum was opened widely, disclosing a further myxoma in the left atrium. Both tumours took origin from the septum, close to the foramen ovale. The common base of both myxomas was widely excised. The septum was sutured transversely, and a dacron graft was not required. Subsequent histology revealed a typical atrial myxoma. The patient made an uneventful postoperative recovery.

\section{Discussion}

Obstruction to blood flow at the atrio-ventricular valve, peripheral embolism and systemic upset account for the majority of the clinical features of atrial myxomas (Sutton et al., 1980). Although occasional patients with myxomas are asymptomatic (Sutton et al., 1980); Morgan et al., 1977), this is unusual. Up to $75 \%$ of cases (Buckley and Hutchins, 1979) occur in females, and the majority are diagnosed in the fifth or sixth decades of life. A family in which one parent and three out of seven siblings had atrial myxomas has also been described (Siltanen $e$ al., 1976).

Diagnosis before surgery or death is unusuad because of the non-specific nature of the symptoms and the unobtrusive and subtle cardiac signs. Such patients frequently present to the general physicia? or the neurologist, rather than the cardiologist, and the diagnosis is unlikely to be made, unless the condition is actively considered.

There are a number of unusual features to the case we have described. In the first place, bi-atriat: myxomas causing recurrent symptomatic pulmonar emboli in the absence of peripheral systemic embog lism is unusual. In fact, recognized embolism is much more frequent in left $(60 \%)$ than in right-sides tumours (8-10\%) (Meller et al., 1977). Secondly, the lack of systemic symptoms, such as malaise, weigh loss, pyrexia and arthralgia, which occur in up to $90 \%$. of cases (Goodwin, 1963), is remarkable, and this is reflected in the relatively minor abnormalities in thes ESR and serum gammaglobulins. Thirdly, there wer\& no symptoms of atrio-ventricular valvular obstruc tion. Despite the fact that the right atrial tumour appeared to fill the entire atrial cavity, and was seef angiographically to move freely within the righ atrium, the patient never had syncope, and did not exhibit signs of cardiac failure. The friction rub noteg 


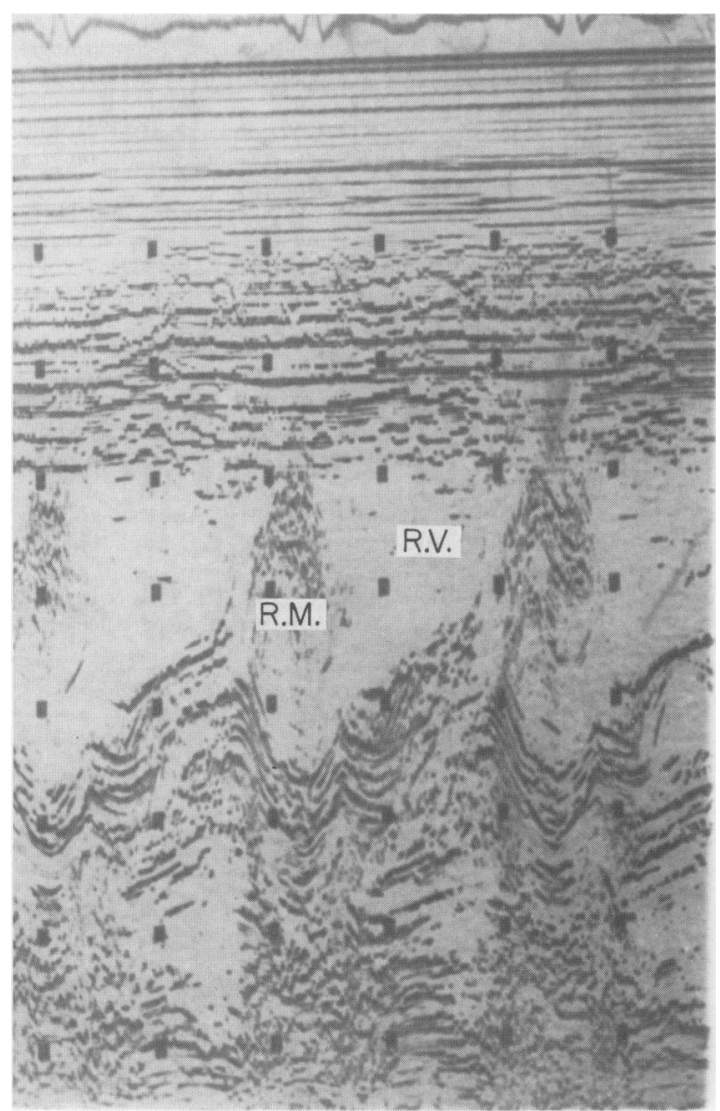

FIG. 2. M-mode echocardiogram showing right atrial myxoma R.V. $=$ Right ventricle. R.M. $=$ Right atrial myxoma behind the anterior leaflet of the tricuspid valve.

in this case is an uncommon ausculatory finding. It has been suggested that this is caused by movement of the myxoma against the endocardium (Frankenfeld, Waters and Steiner, 1960). There was no ECG nor echocardiographic evidence of pericarditis. Finally, the prominent facial freckling is worthy of comment. This has previously been described in two patients with bi-atrial myxomas (Frankenfeld et al., 1960; Dashkoff et al., 1978), and in addition, lentiginosis (Rees, Ross and Keen, 1973), and progressive skin pigmentation (Kendall and Symonds, 1952) have been described in patients with left and right atrial myxomas respectively. It is possible that such dermatological signs occur more frequently, but are not reported.

In 1951, Prichard stated that 'the diagnosis of cardiac tumours is either impossible, or a matter of chance', and that such tumours 'present a dismal diagnostic prospect'. This, however, is now no longer the case, and the reasons are well illustrated by the case we have described. The introduction of echocardiography and angiocardiography is largely responsible for the increasing numbers of myxomas which are now diagnosed during life and pre-operatively (Donahoo et al., 1979; Attar et al., 1980). Angiocardiography, while valuable, can occasionally be hazardous (Pindyck et al., 1972), and give false positive and false negative results (Martinez, Giles and Burch, 1974). For these reasons, echocardiography, and in particular two-dimensional echocardiography is now the preliminary investigation of choice for atrial myxomas (Donahoo et al., 1979). The importance of accurate pre-operative diagnosis is reflected in the increasingly favourable surgical outcome, following the introduction of these imaging techniques (Dashkoff et al., 1978).

Once the diagnosis has been established, surgery should be performed as soon as possible (Attar et al., 1980), with complete removal of the myxomas, including wide excision of their base (Kabbani and Cooley, 1973). Although myxomas may develop in any part of the atria, they most commonly arise, as in our patient, in the region of the foramen ovale, and if bi-atrial, are usually attached to the opposite sides of the inter-atrial septum (Imperio et al., 1980).

At operation, it is important to look for secondary valvular damage caused by the tumour, especially with right atrial myxomas (Attar et al., 1980). There was no evidence of tricuspid or mitral dysfunction in our patient, and she had a satisfactory outcome to surgery.

There have been several reports (Attar et al., 1980; Richardson et al., 1979) of recurrence of atrial myxomas, following surgery, although the true incidence is difficult to ascertain, due to the lack of longterm post-operative follow-up studies. The reported rates vary from $4 \%$ to $14 \%$ (Sutton et al., 1980; Richardson et al., 1979), and have been described as early as 6 months, and as late as 90 months postoperatively (Richardson et al., 1979). Our patient has remained well since surgery was performed 16 months ago, and there is no evidence of recurrence so far. We plan to review her regularly with serial echocardiography.

\section{References}

Attar, S., Chen Lee, Y., Singleton, R., Scherlis, L., David, $R$. \& MCLAughlin, J.S. (1980) Cardiac myxoma. Annals of Thoracic Surgery, 39, 397.

BUCKLEY, B.H. \& HUTCHINS, G.M. (1979) Atrial myxomas: A fifth year review. American Heart Journal, 97, 639.

Carvalho, A.C., Silva, C.O., Gimenes, A.C., Godoy, M.F., Succi, J.E., Miro, M.L.G., Magosso, E.A., HermanN, J.L.V., ANDRAD, J.C.S., BUFFolo, E. \& GALlUCCI, C. (1980) Mixoma biatrial-diagnóstico pré-operatório e remoçao cirúrgica com sucesso. Arquivos Brasileiros de Cardiologia, 35, 235.

DashKoff, N., Boersma, R.B., Nanda, N.C., Gramiak, R., ANDERSEN, M.N. \& Subramanian, S. (1978) Bilateral atrial myxo- 
mas. Echocardiographic considerations. American Journal of Medicine, 65, 361 .

Donahoo, J.S., Weiss, J.L., Gardner, T.J., Fortuin, N.J. \& BRAWLEY, R.K. (1979) Current management of atrial myxoma with emphasis on a new diagnostic technique. Annals of Surgery, 189, 763.

FITTERER, J.D., SPICER, M.J. \& NELSON, W.P. (1976) Echocardiographic demonstration of bilateral atrial myxomas. Chest, 70, 282.

Frankenfeld, R.H., Waters, C.H. \& SteineR, R.C. (1960) Bilateral myxomas of the heart. Annals of Internal Medicine, 53, 827.

GoodwiN, J.F. (1963) Diagnosis of left atrial myxoma. Lancet, 1, 464.

Herpin, D., Boutaud, P., Champeau, C., Badouraly, A., Amiel, A., Morin, J. \& Demange, J. (1980) Les myxomes multicavitaires. Revue de la litterature à propos d'un cas de myxome Bi-auriculaire. Annals de Cardiologie et d'Angéiologie, 29, 531.

Imperio, J., Summers, D., Krasnow, N. \& Piccone, V.A. (1980) The distribution patterns of biatrial myxomas. Annals of Thoracic Surgery, 29, 469.

KABbaNI, S.S. \& Cooley, D.A. (1973) Atrial myxoma. Surgical considerations. Journal of Thoracic and Cardiovascular Surgery, 65,731 .

KenDall, D. \& Symonds, B. (1952) Epileptiform attacks due to myxoma of the right auricle. British Heart Journal, 14, 139.

MARTINEZ, E.C., GILES, T.D. \& BURCH, G.E. (1974) Echocardiographic diagnosis of left atrial myxoma. American Journal of Cardiology, 33, 281.
Meller, J., Teichholz, L.E., Pichard, A.D., Matta, R., Litwak, R. \& HeRMAN, M.V. (1977) Left atrial myxoma. Echocardiogra- $\mathbb{D}$ phic diagnosis and review of literature. American Journal of Medicine, 63, 816 .

Morgan, D.L., Palazola, J., Reed, W., Bell, H.H., Kindred, L.H. \& BeAuChamP, G.D. (1977) Left atrial myxomas. American Journal of Cardiology, 40, 611.

Pindyck, F., PeirCe, E.C. III., Baron, M.G. \& Lukban, S.B. (1972) Embolisation of left atrial myxoma after trans-septal cardia $\bar{C}$ catherization. American Journal of Cardiology, 30, 569.

Prichard, R.W. (1951) Tumours of the heart. Archives of Patho 2 $\log y, 51,98$.

REES, J.R., Ross, F.G.M. \& KEEN, G. (1973) Lentiginosis and left atrial myxoma. British Heart Journal, 35, 874.

RiChaRdSON, J.V., BRANDT, B. III., DOTY, D.B. \& EhrenhaFT, J.L.(1979) Surgical treatment of atrial myxomas: early and late result $\overrightarrow{B u}$ of 11 operations and review of the literature. Annals of Thoracie Surgery, 28, 354.

Siltanen, P., TuUteri, L., Norio, R., Talo, P., Ahrenberg, P. \& HALONEN, P.I. (1976) Atrial myxoma in a family. Americant. Journal of Cardiology, 38, 252.

Sutton, M.G. St John, Mercier, L.A., Giuliani, E.R. \& Lie, J.T: (1980) Atrial myxomas. A review of clinical experience in 48 patients. Mayo Clinic Proceedings, 55, 371.

(Accepted 10 March 1983) 